https://dx.doi.org/10.4314/rjeste.v3i1.9

\title{
Experimental investigation on the potentials of Sisal Fibres as Reinforcements for Drainage Concrete Cover Plates
}

\author{
Leopold Mbereyaho $^{1 a^{*}}$, Francois Twayigize ${ }^{1 \mathrm{~b}}$, Laury Givens Musabe Ishimwe ${ }^{1 \mathrm{c}}$, Sandrine \\ Mutumwinka $^{1 \mathrm{~d}}$ \\ ${ }^{1}$ Department of Civil, Environmental and Geomatics Engineering, University of Rwanda, \\ College of Science and Technology. P.O Box: 3900 Kigali, Rwanda

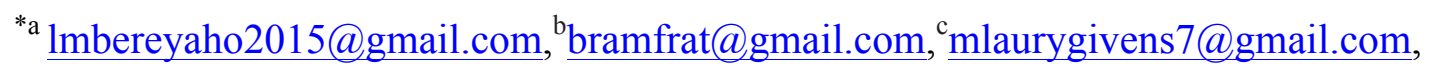 \\ dishimwe352@gmail.com
}

\begin{abstract}
With the development of infrastructures in Rwanda, the roads construction has been one of busiest area, and as the country counts thousands hills the design and construction of drainage systems required a great attention. Most of road drainage channels are covered with concrete plates that are reinforced with ordinary steel bars, while others are not covered due to the high cost of reinforced concrete plates. As the majority of these plates are only subjected to light pedestrian loads, they should be reinforced accordingly. This study was intended to check the potentials of sisal fibres from Agave Sisalana' cactus plant which has shown good results in flexural members, as plates reinforcements. At first the quality of ordinary concrete components was checked. Then some of sisal fibres were prepared, manufactured into ropes of $10 \mathrm{~mm}$ diameter and then used as replacements of main steel bars in concrete plates before their tensile capacity was checked. Other pieces of sisal fibres of $5 \mathrm{~cm}$ length were mixed in concrete mass with different percentages of $0.5 \%, 1 \%$ and $1.5 \%$ of concrete volume. Test results showed that the compressive, tensile and flexural strengths for concrete with $1 \%$ of sisal fibres were more adequate for M30 concrete and therefore able of sustaining the real loads applied to the drainage concrete cover plates. As the performance of natural sisal fibres depends on fibres treatment methods, length, and type of required concrete, further studies on the use of sisal fibres should consider those factors.
\end{abstract}

Keywords: Agave sisalana, drainage channel, Reinforced Concrete, Sisal Fibres, Sisal ropes. 


\section{Introduction}

Recently, Rwanda has known the development of infrastructures, and the roadsconstruction has been one of most busy area. Roads are constructed with drainage channels and most of them are being covered with concrete platesalong the roads.Others were being left uncovered and becoming dangerous, as well as unsafe zones to the public. The covering of all drainage with concrete plates may be an expensive solution mainly due to the cost of materials, especially that some of them are exported from outside the country, while the local material manufacturing industry wasstill only growing. As these plates were not subjected to any heavy traffic load, except the one from pedestrians, especially when drainage channels are separated from the roadway by kerbs, there was a need in the strong but cheaper solution.The Fig.1(a), and Fig.(b) show the difference between the covered and uncovered spaces noted on one of the Kigali City roads.Sisal is a natural fiber derived from the long, green leaves of the 'agave sisalana' cactus plant, and they are very commonly used in Rwanda (Fig.1,c).

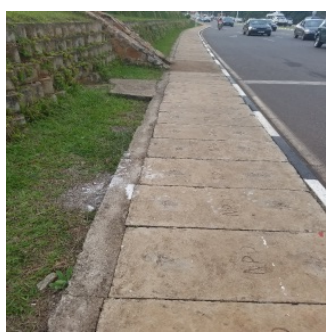

(a)

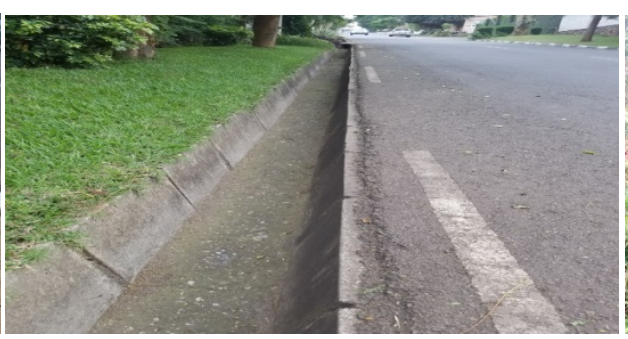

(c)

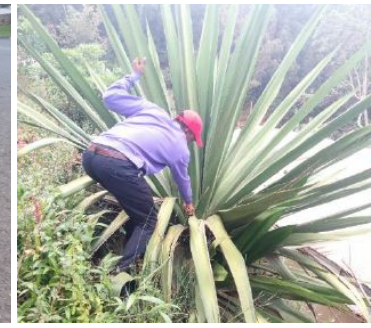

(b)

Fig.1: Covered KN 3 Rd (a),Uncovered KN 25 (b), and Agave sisalana’ cactus plant (c)

Until today, sisal fibres have not been under use as construction materials. For extracting sisal fibre, the leaves are crushed between blunt knives and moisture and the fleshy pulp are removed from the fiber (Naveenet al., 2018). The purpose of this study was the assessment of the potentials of sisal fibres as replacements of ordinary steel reinforcements as local materials for the production of safe but affordable drainage concrete plates. Among others, specific objectives were to analyze the rationale of using Reinforcement Steel bars in drainage plates, to identify strength performance of sisal fibres, to manufacture and test drainage plates with Sisal Fibres, and to conduct a cost estimation to establish the affordability of the new drainage plate. The use 
of natural fibrereinforced composites is now considered as a new perspective in the construction industry (Suryawanshi and Dalvi, 2013). Sisal fiber was found to be a potential reinforcement for polymer composites, with its physical and mechanical behaviors depending on their source, age, and location, but also on their fiber diameter, experimental temperature, gauge length, and strain rate, as well as the manufacturing method (Naveen et al., 2018). Sisal fiber inclusion can effectively reduce the propagation of the cracks in the concrete core(Tan et al., 2017). The use of natural fibres including sisal fibres, among others in structures have been encouraged because they are locally available, cheaper and have some good properties (Sen and Reddy,2011).Also, good physical properties, mechanical performance, and microstructural characteristics of the composites before and after accelerated and natural aging were evaluated (Tonoli et al., 2011).A significant improvement in the overall performance of the cement based composites was observed though the investigation on the possibility of using cellulose fibres including sisal (Reynaldo, 2011). Another potential application of composites reinforced with sisal fibres material may be the replacement of asbestos cement composite, which has got a negative impact to human and animal health and is prohibited in industrialized countries(Aruna, 2014). The addition of fibres not only can increase the tensile strength to the concrete mixes but also can improve some other engineering properties (Priyankaraniand Srichandana, 2015). The use of fiber ropes as a partial replacement of steel bars in concrete beams realized about $75 \%$ of the load capacity of the ordinary reinforced beam (Heniegal, 2017). Sisal fibrescan be used as admixture and offer good properties especially the compressive, tensile as well as Flexuralstrength of concrete, but they are influenced by the fiber length(Bharath and Srikanth, 2017). A comparative study on conventional concrete and sisal fibre reinforced concrete with varying length has also shown the influence of the fibre length in concrete (Dhumal et al., 2018). Sisal fibres may be even a good earth reinforcement material with potential applications in civil engineering, as it was demonstrated by the assessment of mechanical properties of fiberreinforced silty clay (Yankai et al., 2014).

The potentials of sisal fibres as reinforcements in reinforced concrete plate membersare rarely discussed in the current literature, and this is the scope of the presented study. 


\section{Research Methods and Materials}

After the extraction, using scissors, some dried sisals fibres were cut into small pieces of $50 \mathrm{mmlength}$ to be casted with concrete, while others were used into ropes of $10 \mathrm{mmdiameter}$ for use as replacement of steel reinforcements for beam. The following Fig. 2 shows the process of cutting sisal fibres into smaller pieces and roping, as well as the concrete mixing with sisal fibres.
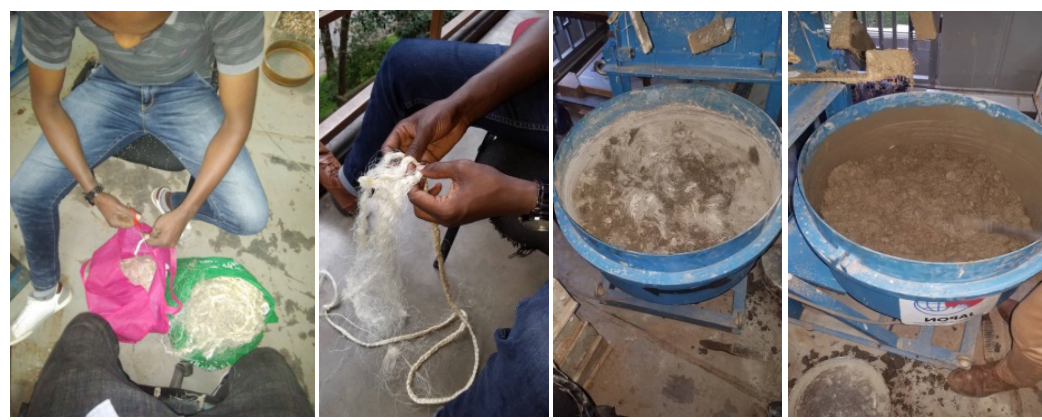

Figure 2: Cutting and roping of sisal fibres and mixing with sisal fibres

The materials components for concrete were locally collected and other bought from the local market:the used aggregates were collected at the local construction company, Real contractors, while the Ordinary Portland Cement (OPC) of 42.5 Grade fromTwiga Cement manufacturing available in local market. The used aggregates had the following properties: Coarse aggregates (CA) nominal size: 20mm, CA specific gravity: 2.66; Fine aggregates (FA) zone: Zone II, and FA specific gravity: 2.61 .

The formwork fabrication: The formwork for drainage concrete plates was made referring to the dimensions of drainage concrete plates, which were: $140 \times 50 \times 10 \mathrm{~cm}$ or $100 \times 50 \times 10 \mathrm{~cm}$ for pedestrians' way. The sizes of beam's formwork are $60 \times 15 \times 15 \mathrm{~cm}$.All dimensions are taken from the interior of the formwork (see Fig.3).

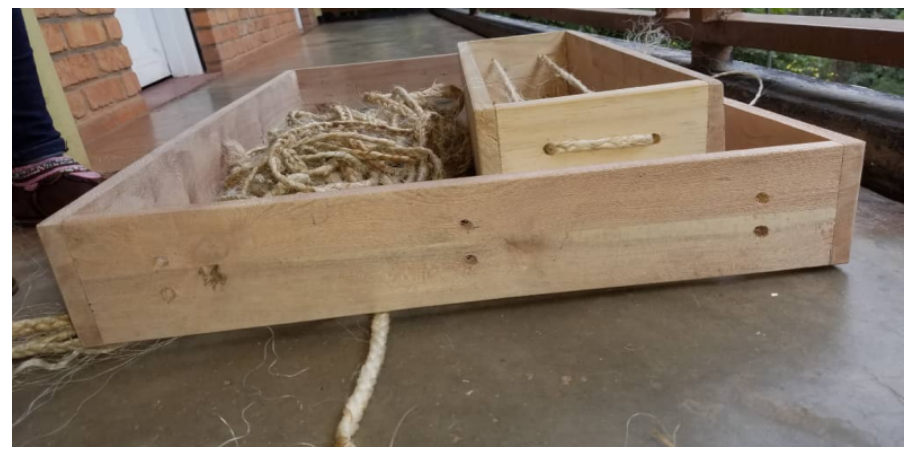


Figure 3: Beam and slab Formwork

During the Mixing of all designed concrete materials namely, cement, aggregates, water and sisal fibres of $50 \mathrm{~mm}$ length composing $0.5 \%, 1 \%$ and $1.5 \%$, of concrete weight. The following quantities were calculated using the concrete mix design procedure recommended by IS $10262-$ 2009, while M30 Concrete mix was selected as suitable by strength requirements for road concrete plates.

$\checkmark$ Water content $=186 \mathrm{~kg}$; Water cement ratio $=0.45$; Cement content $=413.3 \mathrm{~kg}$

$\checkmark$ Volume of concrete $=1 \mathrm{~m}^{3}$; Volume of cement $=0.1312 \mathrm{~m}^{3}$; Volume of water $=0.186$ $\mathrm{m}^{3}$ Volume of aggregates $=0.6828 \mathrm{~m}^{3} ;$ Volume of fine aggregates $=0.2595 \mathrm{~m}^{3}$; Volume of coarse aggregates $=0.4233 \mathrm{~m}^{3}$;

$\checkmark$ Weight of fine aggregates $=677 \mathrm{~kg}$; Weight of coarse aggregates $=1126 \mathrm{~kg}$

From the above quantities, the materials mix ratios fixed as follows:

Water: cement: Fine Aggregates: Coarse Aggregates $=0.45 ; 1: 1.64 ; 1: 2.72$

The testing moulds had respectively the following dimensions: for compressive strength testing:

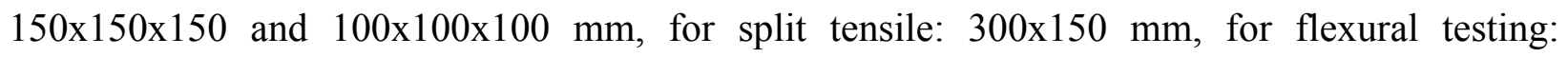
$600 \times 150 \times 150 \mathrm{~mm}$. The following tests of concrete components and concrete samples were done: aggregates sieve analysis and concrete slump tests, tensile strength of sisal fibres ropes, the compressive strength test with different sisal fiber content (the first cubes were controlling cubes with no sisal fibres content; the other cubes contained the sisal fibres in the following percentages: $0.5 \%, 1 \%$ and $1.5 \%$ of total volume of a cube), the sprit tensile test on cylinders with and without sisal fibres, and the flexural strength test on beams reinforced with ordinary steels of $10 \mathrm{~mm}$ diameter and others reinforced with sisal fibres ropes (also of $10 \mathrm{~mm}$ diameter) as steel reinforcements. The cubes, beams and cylinders to be tested were put in a dry place for 24 hours and then the curing took 7 and 28 days. All tests were conducted using three samples and following the procedures as required by Indian standards. The results presented in Figs. $6-8$ are averages from the three tested samples.

The cost estimation for normal concrete plate reinforced with steel bars and concrete plate reinforced with sisal fibres and ropes, was carried out to compare their affordability. The unit 
cost estimation was used. In general the only difference was between the cost of ordinary steel reinforcement and the one for sisal fibres in the local market.

\section{Results and Discussion}

This section presents all results from the study and discusses them against available standards or previous results. The results from Sieve Analysis of the coarse and fine aggregates are presented in Fig. 4 and Fig.5, respectively.

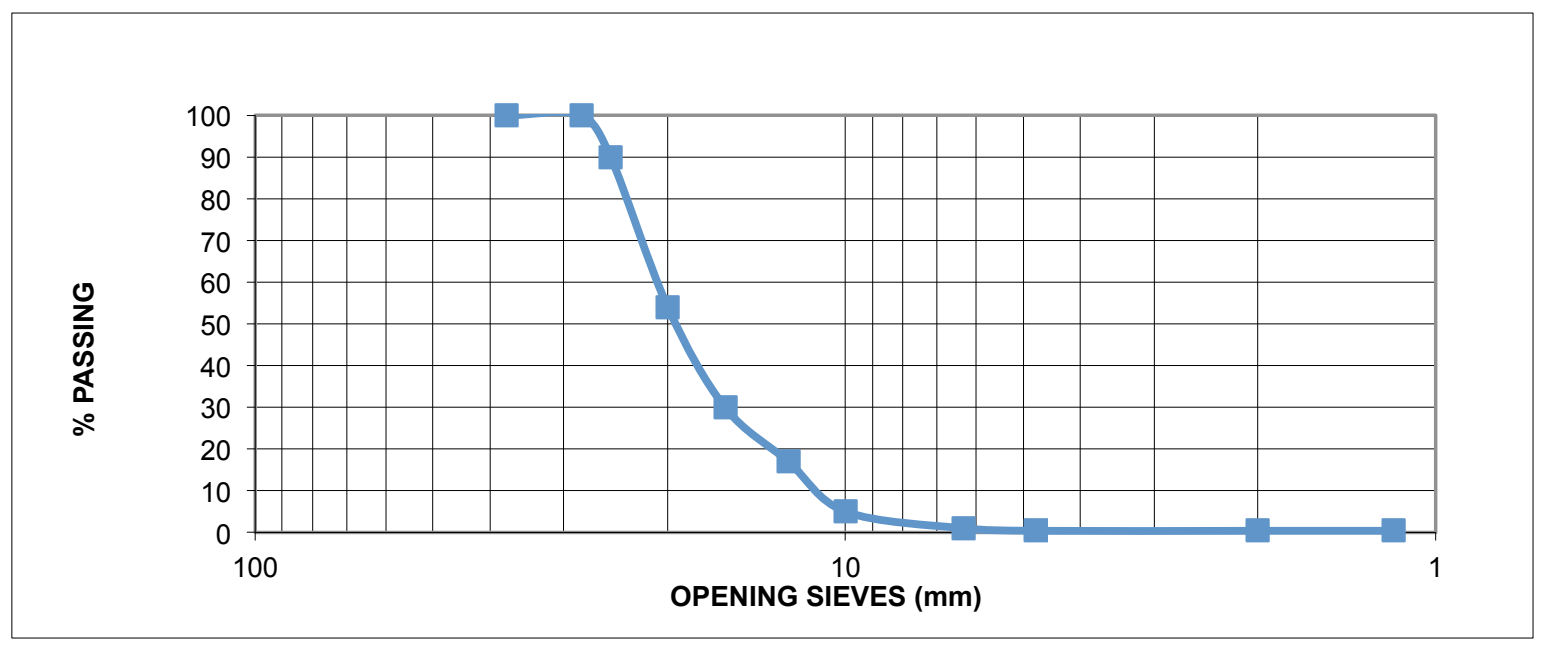

Figure 4: Sieve Analysis of Coarse Aggregate

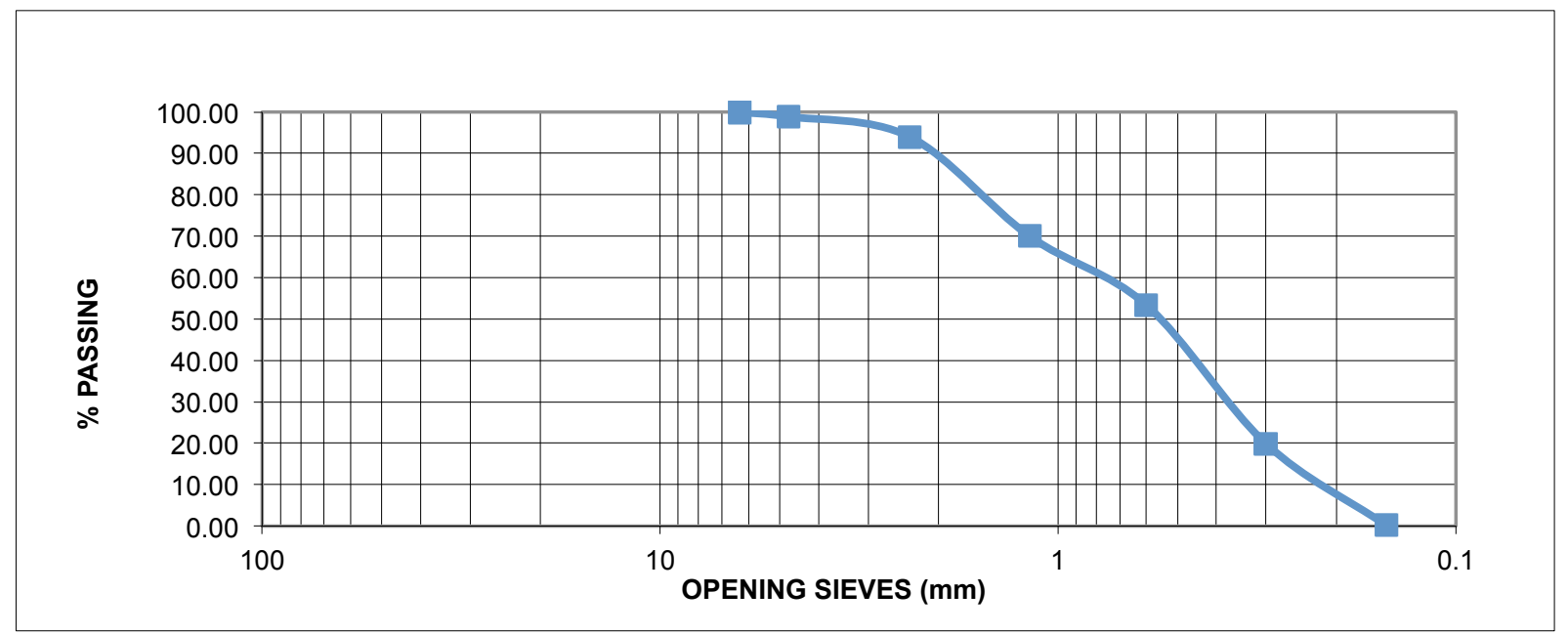

Figure 5: Sieve Analysis of Fine Aggregate 
For CA, the total Cumulative $\%$ of refusal $=701.8$, then the fineness modulus $=$ Total Cum $\%$ Retained $/ 100=701.8 / 100=7.018$. For FA, Total Cumulative $\%$ of refusal $=263.57$ and the fineness modulus $=$ Total Cum $\%$ Retained $/ 100=263.57 / 100=2.64$. According to IS 383-1970, the medium sand should have the fineness modulus ranging between 2.6 and 2.9, while for the zone II, the fineness modulus should range between 3.37 and 2.1.This indicates that the fine aggregates used in this study was medium sand and was from the Zone II. The fineness modulus of coarse aggregates was found equal to 7.018, and was in the range of $5.5-8.0$ recommended by the same standard.

The tensile strength of sisal ropes checked in order to establish its tensile capacity with comparison to ordinary reinforcement. Details are presented in the table 1 below.

Table 1: Tensile Strength of sisal ropes

\begin{tabular}{lccclc}
\hline Sample & Diameter(mm) & $\begin{array}{l}\text { Cross section } \\
\text { Area }\left(\mathrm{mm}^{2}\right)\end{array}$ & Load(N) & $\begin{array}{l}\text { Tensile } \\
\text { strength } \\
\left(\mathrm{N} / \mathrm{mm}^{2}\right)\end{array}$ & $\begin{array}{l}\text { Average } \\
\left(\mathrm{N} / \mathrm{mm}^{2}\right)\end{array}$ \\
1 & & 3900 & 44.6 & \\
2 & 10 & 78.5 & 3600 & 40.8 & 44.0 \\
3 & & & 4100 & 46.5 & \\
\hline
\end{tabular}

From the above table, the tensile strength of sisal ropes was found equal to $44.0 \mathrm{~N} / \mathrm{mm}^{2}$.This established value was in line with results reported in some studies (Aruna, 2014).

The slump test result for fresh concrete was found to be $55 \mathrm{~mm}$, and the values meet well the applied standards.

The results from mechanical tests for samples with sisal fibres percentage of $0 \%, 0.5 \%, 1 \%$ and $1.5 \%$, tested after 7 and 28 days of curing, are presented in Figs. $6-8$. 


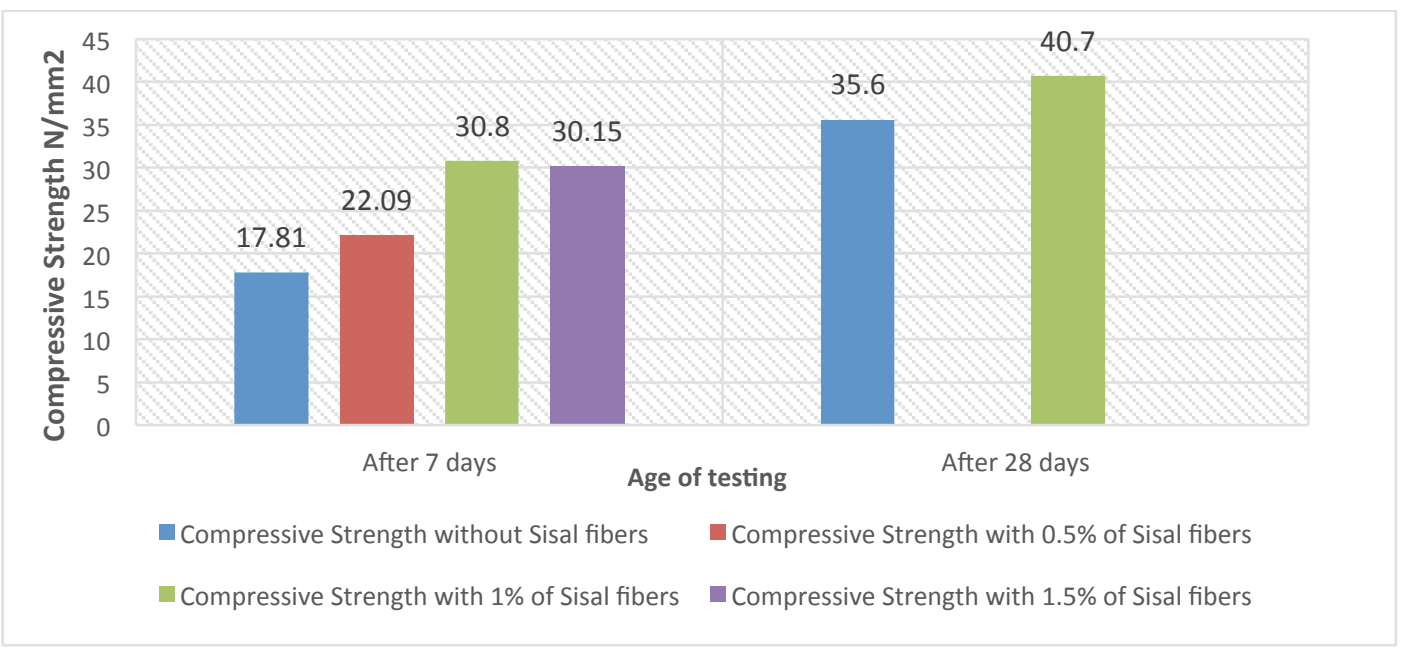

Figure 6: Compressive Strength at 7 and 28 days

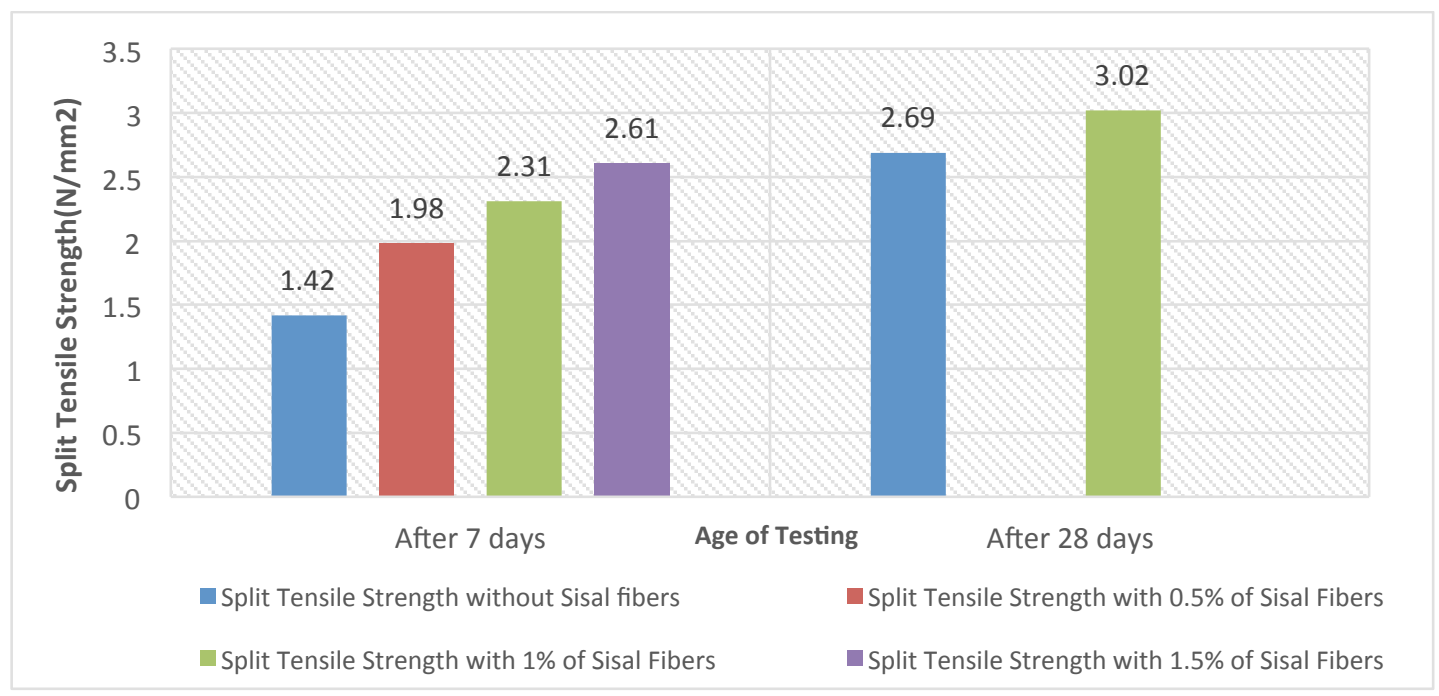

Figure 7: Split Tensile Strength Test Chart 


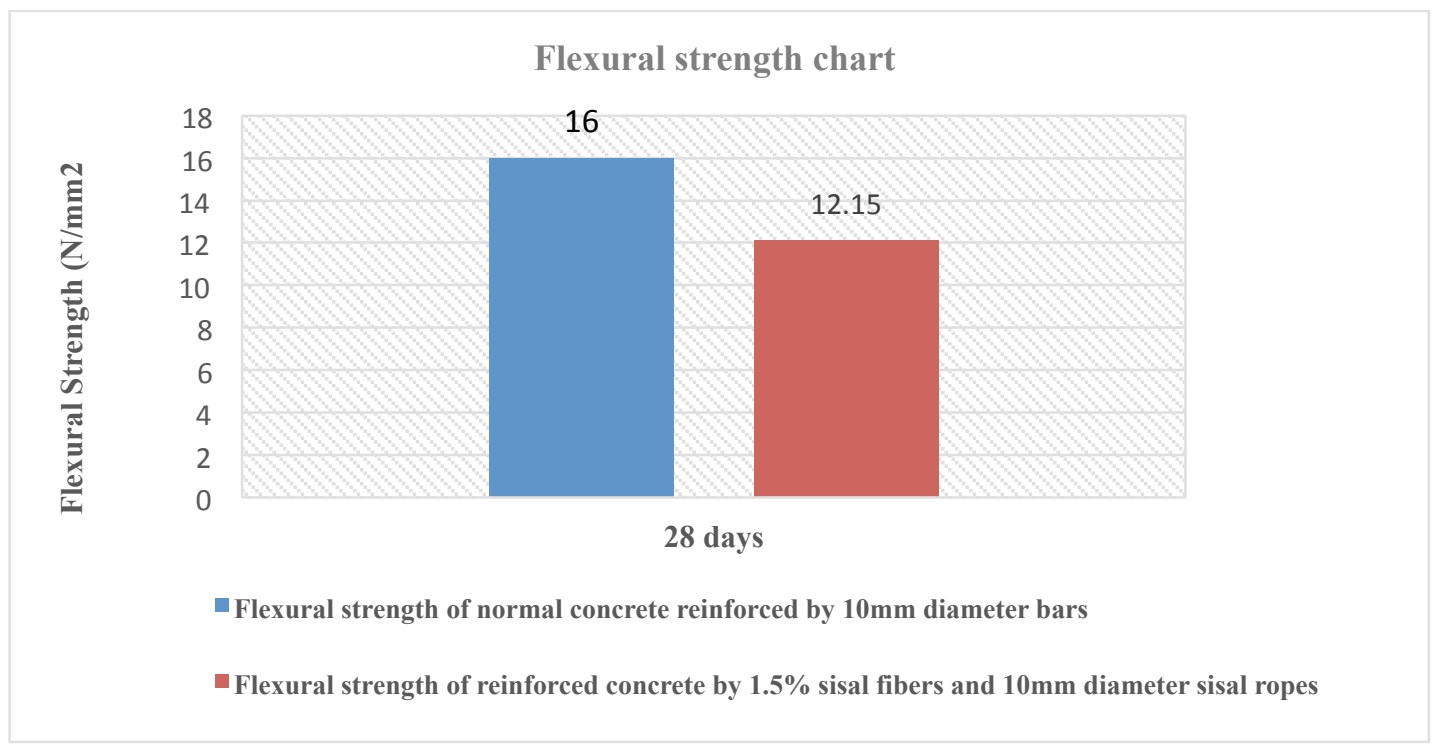

Figure 8: Flexural Strength Test Chart

These mechanical test results are in line with either those from previous studies (Nanak et al., 2013), or those given by standards, as they are summarized in the table 2 presented below.

Table 2: Comparative analysis of concrete plate's strength at $28^{\text {th }}$ day

\begin{tabular}{cccc}
\hline Properties & $\begin{array}{c}\text { Ordinary } \\
\text { reinforced } \\
\text { concrete plate }\end{array}$ & $\begin{array}{c}\text { Sisal reinforced } \\
\text { concrete plate } \\
\text { (with 1\%) }\end{array}$ & $\begin{array}{c}\text { Min Standard values for } \\
\text { M30 (Nanak et al., 2013) }\end{array}$ \\
Compression strength & $35.6 \mathrm{~N} / \mathrm{mm}^{2}$ & $40.7 \mathrm{~N} / \mathrm{mm}^{2}$ & $30 \mathrm{~N} / \mathrm{mm}^{2}$ \\
Split tensile strength & $2.69 \mathrm{~N} / \mathrm{mm}^{2}$ & $3.02 \mathrm{~N} / \mathrm{mm}^{2}$ & $1.9 \mathrm{~N} / \mathrm{mm}^{2}$ \\
Flexural strength & $16 \mathrm{~N} / \mathrm{mm}^{2}$ & $12.15 \mathrm{~N} / \mathrm{mm}^{2}$ & $2.8 \mathrm{~N} / \mathrm{mm}^{2}$ \\
\hline
\end{tabular}

For both compressive and tensile strength, the strength values of concrete with and without sisal fibres increases with age (Fig.5, Fig.6), what is in line with standards and show that not only concrete components are adequate, but also the used sisal fibres don't stop the concrete hardening process. From the table 2, it can be concluded that the plates with sisal fibres are stronger under compression and tension than ordinary plates, while ordinary plates are stronger than plates with sisal fibres under flexure. The flexural strength has reduced up to $24.06 \%$, after replacing steel bars with sisal ropes. However the results show that concrete plates reinforced by sisal ropes are stronger enough to withstand footway loadings without failing (Bharath and Srikanth, 2017). The initial decrease and then increase of both compressive and tensile strengths 
of concrete samples with sisal fibres up to $1 \%$ is confirmed also in different studies (Aruna, 2014; Priyankarani and Srichandana, 2015).

The cost estimation showed that plates with sisal fibres were around 1.85 times cheaper than concrete plates with ordinary reinforcement, with the same sizes.

\section{Conclusion}

Following the earlier set objectives, the study checked first the quality of concrete components and sisal fibres, and established that all of them met standards. Results obtained from compression, split tensile and flexural tests allow concluding that the sisal fibres have a good potentiality to be used as reinforcements in drainage concrete plates up to $1 \%$ of concrete volume. The proposed drainage plate with sisal fibres found to be around 1.85 more affordable than the plates with ordinary steel reinforcement. As the performance of natural sisal fibres would depend on treatment methods, fibres length, and type of required concrete, it is recommended that further studies on the use of sisal fibres consider those factors.

\section{Acknowledgement}

The authors sincerely acknowledge the support from Real Contractors Company for kind support in collection and testing of concrete components. Authors gratitude goes as well to the leadership of Rwanda Standard Board (RSB), IPRC Kigali and Saint Joseph Integrated Technical College for provided support in using their laboratory facilities. Finally the University of Rwanda,College of Science and Technology is acknowledged for all kind of support provided, being technical or moral during this study.

\section{References}

Aruna M., Mechanical Behaviour of Sisal Fibre Reinforced Cement Composite. World Academy of Science, Engineering and Technology International Journal of Materials and Metallurgical Engineering, Vol.4 (4), 2014, pp. 650-653.

Bharath P., A.Srikanth (2017), Effect of Fiber Length and Percentage of SISAL on Strength of Concrete. International Journal of Advanced Research in Science, Engineering and Technology, Vol. 4(9), pp. 4583-4594.

DhumalMukesh, OnkarGajdhane, SumedhGaikwad, VaishnaviBattul (2018). Comparative Study on Conventional Concrete and Sisal Fibre Reinforced Concrete with Varying 
Length.International Journal of Engineering Technology Science and Research IJETSR, $5(5)$.

Heniegal Ashraf Mohame (2017). Performance of concrete beams reinforced with fiber ropes as a partial replacement of steel bars. International Journal of Engineering and Innovative Technology (IJEIT), 7(3), pp. 25-33.

IS 383-1970 Indian Standard Specification for Coarse and Fine Aggregates from Natural Sources for Concrete

IS 10262 (2009): Guidelines for concrete mix design proportioning

Nanak Pamnani J., Verma A.K., Bhatt Darshana R., (2013),Comparision between Mechanical Properties of M30 Grade Self Compacting Concrete For Conventional Water Immersion and Few NonWaterbased Curing Techniques,International Journal of Engineering and Advanced Technology (IJEAT), 3 (2).

Naveen J., M. Jawaid, P. Amuthakkannan, M. Chandrasekar (2018), Mechanical and physical properties of sisal and hybrid sisal fiber-reinforced polymer composites, Mechanical and Physical Testing of Biocomposites, Fibre-Reinforced Composites and Hybrid Composites.https://doi.org/10.1016/B978-0-08-102292-4.00021-7.

Reynaldo M. Pablo (2011), Natural Organic Fiber Meshes as Reinforcements in Cement Mortar Matrix, Proceedings of The 2011 IAJC-ASEE International Conference, Paper 108, INT 302.

Sen Tara, H. N. Jagannatha Reddy (2011), Application of Sisal, Bamboo, Coir and Jute Natural Composites in Structural Upgradation,International Journal of Innovation, Management and Technology, Vol. 2(3).

Srichandana P., Priyankarani, G.(2015), Experimental Study on Effects of Sisal Fiber Reinforced Concrete. International Journal \& Magazine of Engineering, Technology, Management and Research, II(3),pp. 388-392.

Tan Haozhi, Libo Yan, Liang Huang, Ying Wang, Hang Li, Jia-yi Chen (2017), Behavior of Sisal Fiber Concrete Cylinders Externally Wrapped With Jute FRP, POLYMER COMPOSITES, DOI 10.1002/pc.23761.

TonoliG. H. D.; H. Savastano Jr.; S. F. Santos; C. M. R. Dias; V. M. John; and F. A. R. Lahr (2011), Hybrid Reinforcement of Sisal and Polypropylene Fibres in Cement-Based Composites, Journal of Materials in Civil Engineering, Vol. 23(2), p.177 - 187. DOI:10.1061/_ASCE_MT.1943-5533.0000152 
Yankai Wu, Yanbin Li, Bin Niu (2014), Assessment of the Mechanical Properties of Sisal FiberReinforced Silty Clay Using Triaxial Shear Tests, Scientific World Journal.DOI: $10.1155 / 2014 / 436231$

Yogesh RavindraSuryawanshi, and Mr. Jitendra D Dalvi (2013) Study Of Sisal Fibre As Concrete Reinforcement Material In Cement Based Composites; International Journal of Engineering Research \& Technology (IJERT), 2 (3). 